\title{
Integrative proteomics and genomics supports a role for interferon gamma in the pathogenesis of Kaposi sarcoma and finds multiple candidate diagnostic proteins for early detection or prevention
}

\author{
Lynn Amon ${ }^{1}$, Jennifer Gross ${ }^{1}$, Jackson Orem², Innocent Mutyaba ${ }^{2}$, Warren Phipps ${ }^{3,5}$, Kurt Diem ${ }^{6}$, Meei-Li Huang ${ }^{6}$, \\ Lawrence Corey ${ }^{3,4,5,6}$, Martin McIntosh' ${ }^{1}$, Corey Casper ${ }^{1,3,5,7,8^{*}}$
}

From $12^{\text {th }}$ International Conference on Malignancies in AIDS and Other Acquired Immunodeficiencies (ICMAOI)

Bethesda, MD, USA. 26-27 April, 2010

\section{Background}

Kaposi sarcoma (KS) is a common and morbid condition among persons with HIV infection. Strategies for preventing KS or designing better treatment regimens would be aided by the identification of biomarkers for development or progression of KS. Due to the vascular and often disseminated nature of KS, proteomic signatures detected from and specific to KS tumors may yield viable candidate diagnostic protein markers and insights into the pathogenesis of KS.

\section{Methods}

Flash-frozen punch biopsies from cutaneous samples of tumor and normal skin of individuals having epidemic (HIV-positive) or endemic (HIV-negative) KS were profiled using tandem mass spectrometry. Protein data were integrated with previously existing databases relevant for prioritizing diagnostic marker candidates, including plasma proteome data of cancer-free individuals, normal endothelial cells, and microarrays profiling the mRNA of KS, normal skin, KSHV-infected endothelial cells, and uninfected cells.

\footnotetext{
*Correspondence: ccasper@fhcrc.org

${ }^{1}$ Public Health Sciences, Fred Hutchinson Cancer Research Center, Seattle, WA, USA

Full list of author information is available at the end of the article
}

\section{Results}

In a comparison of $13 \mathrm{HIV}+$ tumor punch biopsies to $5 \mathrm{HIV}+$ normal samples, 5100 total proteins were identified. We have identified proteins abundant in the majority of tumor samples and absent from normal skin and plasma of cancer-free individuals that may serve as candidate diagnostic markers. Aligning the data with KS tissue expression data produced 72 proteins that were over-abundant in KS samples in both proteomic and transcriptomic datasets. Most notably, a third of those proteins (24 total) are known to interact with interferon gamma (IFN $\gamma$ ) (enrichment p-value $<10^{-8}$ ). Gene symbols are shown in Figure 1. This finding is consistent with previous observations on the importance of IFN $\gamma$ in endothelial cell proliferation and expression in KS tumors. We are currently evaluating these results further, including conducting other experiments intended to compare the KS proteomics signatures that distinguish 6 HIV+ and 6 HIV- KS tumors. Preliminary results from these analyses will be presented as well.

\section{Conclusions}

The combined use of genomic and proteomic interrogation of biopsy material from KS tumors has revealed a large set of proteins that are overexpressed in KS compared to normal skin and provides a set of candidate diagnostic proteins for the prevention or early detection of KS. These data are also useful in exploring 


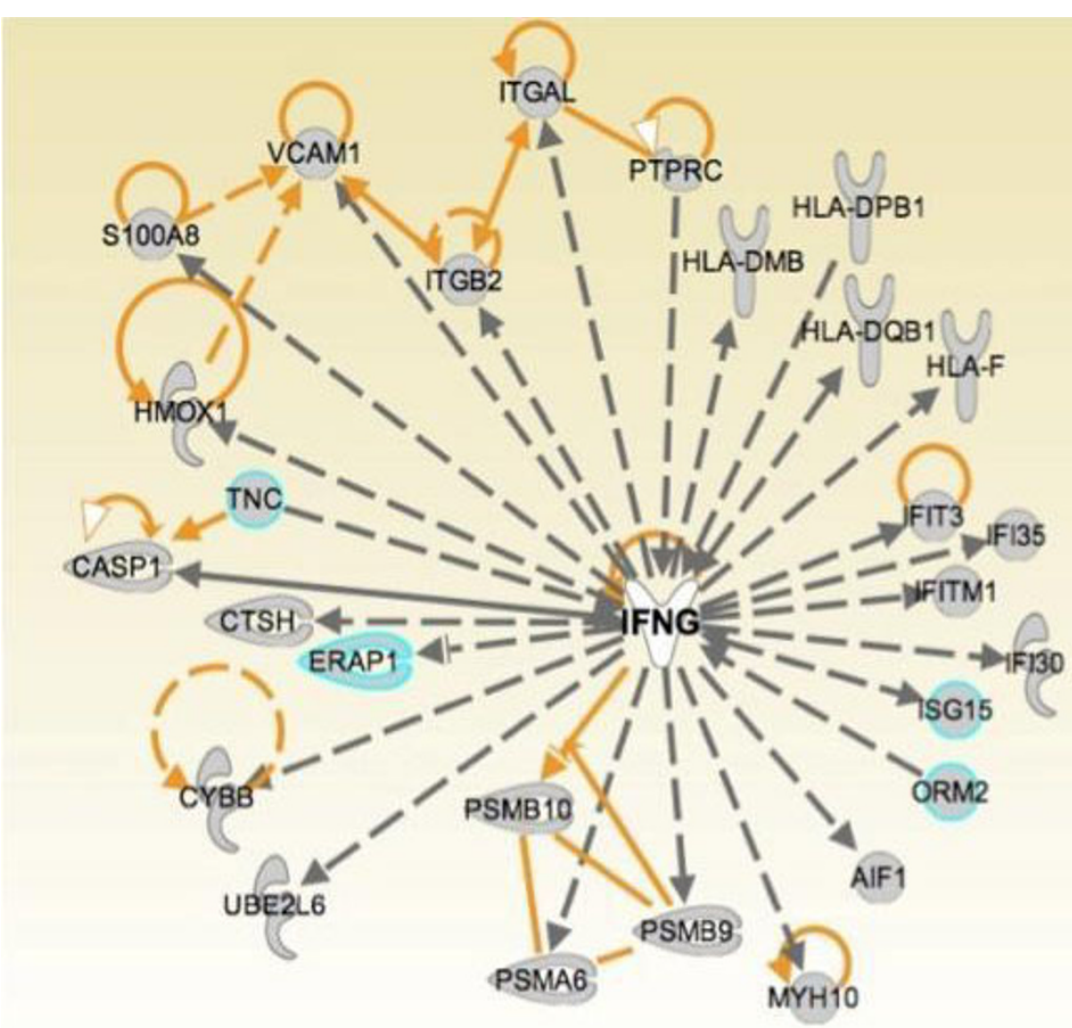

2000-2010 ingenulty Systems, inc. All rights reserved

Figure 1 Tumor proteins with direct or indirect relationships to IFN $\gamma$.

hypotheses regarding the pathogenesis of KS and relating those mechanisms to their role in endemic and epidemic disease.

\section{Acknowledgements}

This article has been published as part of Infectious Agents and Cancer Volume 5 Supplement 1, 2010: Proceedings of the $12^{\text {th }}$ International Conference on Malignancies in AIDS and Other Acquired Immunodeficiencies (ICMAOI). The full contents of the supplement are available online at http://www.biomedcentral.com/1750-9378/5?issue=S1.

\section{Author details}

'Public Health Sciences, Fred Hutchinson Cancer Research Center, Seattle, WA, USA. ${ }^{2}$ Uganda Cancer Institute, Kampala, Uganda. ${ }^{3}$ Vaccine and Infectious Disease Institute, Fred Hutchinson Cancer Research Center, Seattle, WA, USA. ${ }^{4}$ Clinical Research Divisions, Fred Hutchinson Cancer Research Center, Seattle, WA, USA. ${ }^{5}$ Department of Medicine, University of Washington, Seattle, WA, USA. ${ }^{6}$ Department of Laboratory Medicine, University of Washington, Seattle, WA, USA. ${ }^{7}$ Department of Epidemiology, University of Washington, Seattle, WA, USA. ${ }^{8}$ Department of Global Health, University of Washington, Seattle, WA, USA.

Published: 11 October 2010

doi:10.1186/1750-9378-5-S1-A42

Cite this article as: Amon et al:: Integrative proteomics and genomics supports a role for interferon gamma in the pathogenesis of Kaposi sarcoma and finds multiple candidate diagnostic proteins for early detection or prevention. Infectious Agents and Cancer 2010 5(Suppl 1):A42.

\section{Submit your next manuscript to BioMed Central} and take full advantage of:

- Convenient online submission

- Thorough peer review

- No space constraints or color figure charges

- Immediate publication on acceptance

- Inclusion in PubMed, CAS, Scopus and Google Scholar

- Research which is freely available for redistribution 